\title{
LA PRUEBA CIENTÍFICA DE ADN EN EL PROCESO PENAL
}

\section{THE SCIENTIFIC TEST OF DNA IN THE CRIMINAL PROCESS}

Edvar Alberto Cueva Castro

Universidad de San Martín de Porres

ecuevac@usmp.pe

Perú

\section{SUMARIO}

- Introducción

- La valoración racional de la prueba y el objetivo institucional de la búsqueda de la verdad en el proceso penal

- La prueba científica en el proceso penal

- El valor probatorio de la prueba de $\mathrm{ADN}$ en el proceso penal peruano

- Conclusiones

- Fuentes de información

\section{RESUMEN}

La valoración de la prueba pericial científica de $\mathrm{ADN}$ en el proceso penal debe partir por desterrar algunos mitos $\mathrm{y}$ paradigmas, que muchas veces han dificultado o excluido el control de este medio de prueba por parte del Juez penal.

Así, la cientificidad de la prueba de $\mathrm{ADN}$ no puede excluir la valoración por parte del Juez que debe enfocarse, por un lado, en el análisis del procedimiento pericial, conforme a los estándares científicos establecidos y por el otro lado, la fiabilidad de sus conclusiones plasmadas en el informe pericial científico de ADN. De esta manera, el Juez actuará como un epistemólogo que no asumirá la posición de científico sino de evaluador de la correctitud de esta prueba científica y emitirá una valoración con los demás medios de prueba disponibles. Esta posición ha sido asumida por nuestra Corte Suprema de Justicia que, en el Acuerdo Plenario $\mathrm{N}^{\circ}$ 4-2015/CIJ-116, ha brindado criterios de valoración inspirados en los establecidos en el sistema norteamericano a partir del caso Daubert.

\section{ABSTRACT}

The assessment of the scientific expert DNA test in the criminal proceedings must be based on banishing some myths and paradigms, which have often made it difficult or excluded to control this means of proof by the criminal judge. Thus, the scientificity of the DNA test cannot exclude the assessment by the Judge which must focus, on the one hand, on the analysis of the expert procedure, in accordance with established scientific standards and on the other hand, the reliability of its conclusions resulted in the DNA scientific expert report.

In this way, the Judge will act as an epistemologist who will not assume the position of scientist but as an evaluator of the correctness of this scientific test and issue an assessment with the other available means of proof. This position has been assumed by our Supreme Court of Justice that in The Plenary Agreement No. 42015/CIJ-116, it has provided valuation 
criteria inspired by those established in the American system from the Daubert case.

\section{PALABRAS CLAVE}

Prueba pericial científica; AND; valoración de la prueba penal; estándar Daubert

\section{KEYWORDS}

Scientific test; DNA; assessment of the criminal evidence; Daubert standard

\section{INTRODUCCIÓN}

La búsqueda de certeza subjetiva como grado de conocimiento establecido por cierto sector de la doctrina y la jurisprudencia en materia penal, al cual se debe llegar para acreditar la responsabilidad penal del procesado es uno de los objetivos institucionales del proceso penal. Y para cumplir con este objetivo, el proceso penal brinda los medios de prueba para que el juez pueda valorar y motivar si llega o no a ese estado cognitivo. Es, pues, mediante la actividad probatoria desarrollada a lo largo del proceso penal con estricto respeto de los principios y garantías constitucionales, que se llega a la certeza subjetiva y finalmente concluye con la motivación de dicha posición en la sentencia penal.

No obstante ello, existe en la práctica penal casos que abarcan delitos cuyas particularidades son complejas, tal es el caso de los delitos contra la libertad sexual, contra la administración pública y corrupción de funcionarios o también los delitos considerados no convencionales, como el delito de lavado de activos y el tráfico ilícito de drogas. Estos delitos que constituyen y abarcan gran parte del fenómeno criminal nacional, son todo un reto, no solo para los sujetos procesales que se dedican a la investigación criminal o la defensa de los presuntos responsables, sino también para la judicatura, que debe resolver estas cuestiones.
En ese escenario, es inevitable recurrir a la consulta de especialistas de una determinada rama del saber humano, para que de acuerdo con su conocimiento científico y experiencia puedan despejar las interrogantes del juzgador, quien desde luego no puede saberlo todo. A estos especialistas se les conoce como peritos y su labor es la actividad pericial, en base a la cual se obtiene el medio de prueba que es la prueba pericial o prueba pericial científica

Valga esta pequeña introducción para demostrar la importancia del tema que se aborda en el presente artículo, que se centra en la prueba pericial científica $\mathrm{y}$, en específico, en la prueba científica de $\mathrm{ADN}$, tema en el cual se desarrollará primero las bases de la valoración racional de la prueba y su relación con la verdad en el proceso penal; luego la prueba científica de $A D N$, el mito de su infalibilidad dado su carácter científico, su procedimiento y cuidados en la recogida de los elementos de prueba; $y$, finalmente, su valoración en los delitos sexuales conforme a los criterios establecidos por la doctrina y jurisprudencia internacional y nacional.

Esperamos que este esfuerzo investigativo contribuya a conocer mejor los aspectos esenciales de este medio de prueba y al debate académico, para propiciar un análisis serio de esta institución y a desterrar finalmente los mitos que aquejan no solo a la dogmática sino también a la jurisprudencia nacional, que muchas veces obvia motivar este medio de prueba apoyándose en una cientificidad absoluta que presuntamente la excluye de márgenes de error.

\section{LA VALORACIÓN RACIONAL DE LA PRUEBA Y EL OBJETIVO INSTITUCIONAL DE LA BÚSQUEDA DE LA VERDAD EN EL PROCESO PENAL}


El tránsito de un código de procedimiento penal a un código procesal penal implica, además de un mero cambio normativo, un cambio de concepción acerca de las funciones, objetivos y fines del proceso penal. En tal sentido, unas preguntas clave que en el ámbito académico nacional no se han discutido con la debida profundidad, se refieren a: ¿Qué verdad puede obtenerse en el proceso penal? Y ¿la búsqueda de la verdad es un fin u objetivo institucional del proceso? Como vemos, ambas preguntas deben ser debatidas académicamente por la teoría general del proceso penal o por la dogmática del proceso penal, sin embargo, para no extralimitarnos en nuestros propios objetivos del presente artículo de investigación, simplemente tomaremos posición sobre ambos temas de manera concreta.

El proceso penal como todo proceso jurisdiccional tiene un objeto sobre el cual se estructura el funcionamiento del mismo. Para el proceso penal, su objeto no es otro que la pretensión penal, es decir, la imputación penal que "permite designar con una expresión bastante neutra las diferentes fases de sospecha por las que pasa el objeto del juicio del proceso penal a lo largo de su trayectoria" (Nieva, 2012, p. 27); así se entiende, que a diferencia de la pretensión civil que se fija directamente en la demanda, en el proceso penal nos encontramos en un escenario en que la imputación penal es progresiva y se va construyendo desde su planteamiento en la Disposición de inicio de diligencias preliminares hasta la acusación fiscal.

Teniendo claro el objeto del proceso penal, vemos que cada uno de los sujetos procesales, la fiscalía como la defensa, postularán sus respectivas tesis que contendrán afirmaciones fácticas y jurídicas sobre lo que ha sucedido, las cuales, tendrán que estar respaldadas por los medios de prueba que consideren pertinentes y útiles. En este contexto, se ha señalado de manera general sobre la prueba, que tiene la función de servir de aporte cognitivo epistemológico y racional al juez para determinar si alguna de estas afirmaciones sobre la ocurrencia de los hechos es verdadera o no, como señalan Taruffo (2008) y Ferrer (2007). Este concepto es aplicable al proceso penal, por cuanto al asumir un modelo cognoscitivo de averiguación de los hechos, tal y como lo ha postulado Ferrajoli (1995), necesariamente se debe buscar que los medios de prueba aportados puedan perseguir la verdad de los hechos, aun cuando no se consiga la verdad material o correspondencia objetiva con la realidad.

Dicho esto, la verdad a la que se puede aspirar en el proceso judicial es solo una verdad formal o procesal y, para el proceso penal en concreto, se debe asumir una postura coherente con el establecimiento de la verdad como un objetivo institucional del proceso, como apunta Ferrer (2007). En este aspecto, el planteamiento de Guzmán (2011), nos parece coherente al asumir la concepción semántica de la verdad de Tarski, mediante el cual se podría obtener por un lado dos significados de verdad sobre la afirmación de los hechos:

En el primero, se establecerán las condiciones del uso del término verdadero, es decir el significado del término verdad, y en el segundo, se hará referencia a las condiciones frente a las cuales puede considerarse aceptable la utilización del término verdadero en torno a un enunciado (p. 73).

Resulta necesario que en el proceso penal se aporten medios de prueba que epistemológicamente sean de utilidad para el esclarecimiento de los hechos. Estos medios de prueba tienen que ser valorados por criterios racionales, como son los que aporta la lógica, la ciencia y las máximas de experiencia; en ese sentido, cuando se tiene un medio de prueba que por su naturaleza 
aporte conocimientos científicos, el Juez tendrá que recurrir a los estándares o criterios científicos propios de la especialidad para acreditar su contenido, ello sucede, por ejemplo, en el caso de la prueba pericial. Por ello, en el proceso de valoración probatoria, el juez primero tiene que comprender los aspectos generales del conocimiento científico que se pretende analizar, los que pasan por la idoneidad del perito científico, el procedimiento pericial y por supuesto, las conclusiones del informe pericial.

\section{LA PRUEBA CIENTÍFICA DE ADN EN EL PROCESO PENAL.}

\section{Prueba pericial y prueba científica.}

El interés por el conocimiento científico en el proceso penal, ciertamente, no es algo reciente. Ya la doctrina procesal desde el siglo pasado, ha precisado que la cientificidad de la prueba debería entenderse respecto a la estructuración de la convicción "del juez para designar los casos el juicio de inferencia probatoria, que están en la base de la constatación del hecho, comporta para el juez el empleo de conocimientos que van más allá del saber del hombre medio" (Denti, 1974, p. 267); y más recientemente que se "trata de nociones y metodologías científicas necesarias para la conformación de la prueba o la valoración de las hechos" (Taruffo 2008 p. 278), de tal manera que sirve como aporte cognoscitivo de los hechos para el juez del proceso.

Un tema inherente a esta temática es la relacionada a la diferencia entre prueba pericial y prueba científica. En ese sentido, la doctrina procesal ha señalado que "es bastante común que la prueba científica se forme y aporte al proceso mediante un perito. Sin embargo, la prueba pericial no siempre implica el recurso a conocimientos específicamente científicos" (Taruffo, 2008, p. 277); sin embargo, la mayoría de las veces se las asocia, tal y como sucede en el proceso civil español, que a decir de Abel (2012):
En el proceso civil español se utiliza el término prueba científica cuando una actividad probatoria, casi siempre pericial, se ha desarrollado empleando tecnologías que arrojan resultados altamente fiables. El ejemplo paradigmático es el relativo a los análisis de ADN para determinar la paternidad en los juicios de filiación (p. 243).

\begin{abstract}
Al respecto, un primer punto de partida es establecer qué se entiende por ciencia. La cientificidad de un medio de prueba en el proceso judicial se encuentra determinada por el carácter científico que la comunidad le otorga a una rama del conocimiento humano. De ahí que en el proceso judicial y en la mente de los jueces, se encuentre arraigada la diferencia entre las ciencias naturales o empíricas que como la genética, la biología o la ingeniería aportan un conocimiento producto de la aplicación de un método científico y criterios racionales ampliamente aceptados; y por otro lado, las ciencias humanas o sociales como la psicológica, sociología o la economía, consideradas como ciencias suaves.
\end{abstract}

En cuanto a la valoración de la primera clasificación, se le otorga una calidad científica inherente, mientras que, en el caso de las segundas, como refiere Taruffo (2008) "quedan a menudo confiadas a la cultura del juez, considerado como exponente típico del conocimiento común" (p. 281). Sin embargo, ello en la actualidad ya no es suficiente, por cuanto, algunas de estas ciencias sociales o humanas por su tratamiento metodológico y sus resultados contrastables en la praxis, han adquirido una calidad científica que se encuentra respaldada por una comunidad cada vez más amplia, tal y como es el caso de la pericia psicológica, cuyos estudios han 
contribuido también en el contexto judicial mediante la especialización de la psicología del testimonio en adultos o menores.

Por ello, consideramos que en la actualidad existen mitos relacionados con la prueba científica que merecen ser desestimados por ser contra epistemológicas y terminar de otorgarle una fiabilidad excesiva que puede entenderse más no justificarse y que resultan inoperantes en el contexto judicial. Así, la polémica entre prueba científica y prueba pericial, debe dar como resultado un entendimiento de ambos medios de prueba que contribuyan al objetito institucional de búsqueda de la verdad en el proceso penal, que ya no pasa por una diferencia en la denominación, sino en que el tratamiento procesal debe facilitar un contradictorio eficiente que permita el máximo control de fiabilidad de dichos medios de prueba.

En nuestro sistema procesal penal, tenemos el artículo 172 del Código Procesal Penal de 2004 (CPP de 2004 en adelante) que establece en el inciso 1 que: "La pericia procederá siempre que, para la explicación y mejor comprensión de algún hecho, se requiera conocimiento especializado de naturaleza científica, técnica, artística o de experiencia calificada"; es decir, la prueba denominada científica vendría a ser una especie de prueba pericial que también abarca otras especialidades como la técnica, artística o de experiencia calificada, lo que permite un control de la prueba científica conforme a las reglas de la prueba pericial.

Considerar a la prueba científica como una especie de prueba pericial permite asentarla en la realidad de los hechos, de esta manera "el conocimiento del perito no puede ser una simple abstracción del dato técnico, con simple valor simbólico, sino que debe conectar con las restantes operaciones y valores agregados que justifican su utilización en el ámbito de la decisión judicial" (Pabón, 2015, p. 45). La doctrina procesal penal, respecto a la pericia ha señalado que:

Es el medio probatorio con el cual se intenta obtener, para el proceso, un dictamen fundado en especiales conocimientos científicos (v.gr., individualización genética - ADN-), técnicos (v.gr., identificación de matrículas identificadoras de armas, vehículos, etc.) o artísticos (v.gr., determinación de autenticidad de cuadros), útil para el descubrimiento o la valoración de un elemento de prueba (Caferatta y Harabedian, 2008, p. 67).

De similar manera, también ha sido definida por Gómez (citado por Climent, 2005) como "aquella que se realiza para aportar al proceso las máximas de la experiencia que el juez no posee o puede no tener y para facilitar la percepción y la apreciación de los hechos concretos objeto del debate" ( $p$. 735). Asimismo, Cafferata (1998) refiere que "es el medio probatorio con el cual se intenta obtener, para el proceso un dictamen fundado en especiales conocimientos científicos, técnicos o artísticos, útil para el descubrimiento o la valoración de un elemento de prueba" (p. 53), sin que ello signifique como bien precisa el autor, que ello venga a suponer que su actuación en el proceso penal queda supeditado a una deficiente formación del juez en alguna área de conocimiento, sino que, es necesario de un especialista que ilustre desde un área de especialización muy particular.

Asumiendo esta concepción, la doctrina nacional se ha mostrado de acuerdo en considerar acertada la regulación del art. $172^{\circ}$ del CPP de 2004 que considera la prueba pericial puede versar sobre los conocimientos científicos, como señalan Talavera (2009), Neyra, (2010) y San Martín (2015); no obstante, a pesar de considerarla como una prueba pericial y, por lo tanto, su procedimiento y actuación 
se rigen bajo sus reglas procedimentales, es inevitable precisar que la diferencia más resaltante se evidenciará al momento de su valoración por parte del juez penal, ya que dicho control se realizará en tres momentos: el control de la metodología científica empleada, su calidad técnica y, finalmente, su margen de error o falibilidad, como apunta San Martín (2015). Por ello, "cuanto más técnica sea la cuestión sometida a decisión judicial, mayor importancia adquiere la pericia" (Witthaus, 1991, p. 21).

\section{Mitos y paradigmas de la prueba científica}

En este aspecto, la doctrina ha sido clara al establecer que la prueba científica ha sido revestida de una serie de mitos y paradigmas que han influido en su valoración probatoria por parte de los jueces, lo que, sin duda, tiene efectos epistemológicos. En ese sentido, para Gascón (2010) los mitos y paradigmas en la prueba científica se manifiestan en dos aspectos centrales: se le atribuye una valoración probatoria plena respecto de lo que se quiere probar y la presunción de la infalibilidad de sus resultados; ello, proviene, como hemos manifestado de una concepción que pretende dejar al juez al margen de todo tipo de intervención en la valoración probatoria de la prueba científica.

Desde esta perspectiva, el primer aspecto se encuentra referido a la valoración probatoria plena que se le otorga a la prueba científica para probar un determinado hecho. Para Gascón (2010), esta concepción o prejuicio sobre la prueba científica genera la existencia de dos paradigmas: el paradigma de la individualización y el paradigma de la verosimilitud. Respecto del primer paradigma, "se asienta sobre la supuesta capacidad de llegar a identificar plenamente a un individuo o a un objeto a partir de sus vestigios" (Gascón, 2010, p. 85); por ejemplo, si se tiene una muestra de sangre obtenida del lugar de los hechos, necesariamente el análisis científico realizado sobre dicha muestra tendría como resultado la identificación de una fuente que excluiría cualquier otra explicación o resultado distinto.

En efecto, la prueba científica por su propia metodología y resultados permite obtener conclusiones muy próximas a la certeza, así pues:

El método o sistema aplicado trabaja sobre presupuestos a comprobar, y el análisis sobre la cosa o personas, puede ser racional y falible, o exacto y verificable. En el primer grupo (..) en las matemáticas, el resultado siempre es cierto" (Gozaini, 2012, p. 169).

Por ello, es que uno de los paradigmas es el afirmar que el juez debería tener confianza plena en los resultados de este medio de prueba.

Por otro lado, el paradigma de verosimilitud puede entenderse desde la formulación de tres preguntas puntuales: ¿Cuáles son los hechos que aportan los resultados de la prueba científica? ¿Cuáles son los aspectos que deben creerse de estos resultados? Y finalmente, ¿Qué se debe hacer con lo expuesto? La respuesta a estas preguntas tienen por finalidad hacer una diferencia de funciones entre el perito y el juez, ya que, respecto a la primera pregunta, es evidente que es el especialista o científico quien debe identificar el aporte de los resultados que deben ser explicados conforme al conocimiento aplicado; en cuanto a la segunda y tercera pregunta, requieren la intervención valorativa del juez que se servirá de lo expresado en la prueba científica y de otros medios de prueba disponibles y actuados (Gascón, 2010).

Por ello, con razón se puede afirmar que el paradigma de verosimilitud contribuye al desarrollo de mejores controles de la prueba 
científica, ya que, reconoce por un lado el gran aporte epistemológico de este medio de prueba, pero por el otro, no se queda con ello, sino que, proporciona nuevos criterios que proporcionan al juez la legitimidad para ejercer un control probatorio enfocado en la determinación de su fiabilidad y los estándares de probabilidad que aporta al descubrimiento de los hechos en el proceso penal.

Dicho esto, no queremos dar a entender que la cualidad de la prueba científica, de contar con estándares objetivos y científicos que permiten aproximarnos en un grado de probabilidad muy cercano a la certeza, constituye una desventaja para el juzgador; por el contrario, consideramos que son las concepciones erróneas sobre su infalibilidad y que propugnan la exclusión del ejercicio de control y valoración por parte del juez, las que generan ciertamente efectos contra epistemológicos. En ese sentido, coincidimos con Taruffo (2010) cuando afirma que: "La tarea del juez consiste en controlar la validez científica y la corrección del método que el perito ha aplicado, esto es, en verificar el fundamento racional y epistémico de lo que el perito ha hecho" (p. 259).

Asumiendo esta posición académica, en las siguientes líneas se abordarán los aspectos esenciales del procedimiento de la prueba científica de $\mathrm{ADN}$, para luego incidir en los criterios de valoración que se han establecido por la doctrina y la jurisprudencia penal nacional, como desde la perspectiva comparada en lo que sea aplicable a nuestros fines.

\section{Elementos $y$ procedimiento: la importancia de la cadena de custodia.}

La prueba científica de $\mathrm{ADN}$ ha tenido una gran relevancia en los procesos judiciales por la amplia aceptación de su método científico que la sitúa como uno de los medios de prueba más fiables, para aportar conocimiento especializado -en específicoal proceso penal. Ello, ciertamente, se debe a un largo trayecto científico de los estudios en genética forense que le han permitido lograr el prestigio del que ahora goza, pues se sustenta en la individualidad única que nos distingue como seres humanos. Así, si queremos identificar a una persona a partir de su contenido genético, veremos que cada persona tiene una determinada secuencia genética que la distingue del resto, por lo que, con acierto, afirma Gascón (2007):

El potencial de la huella genética es de tal magnitud que su uso en los tribunales se ha convertido ya en moneda corriente. Son muchas las posibles aplicaciones forenses de la prueba, aunque los tipos de pericias más comunes son la investigación biológica de la paternidad, la resolución de problemas de identificación y la investigación de indicios en criminalística biológica, es decir, el análisis de muestras biológicas de interés criminal, como manchas de sangre, saliva, esperma o pelos. En los últimos años, además se han ido desarrollando nuevas tecnologías de identificación por $\mathrm{ADN}$ que han permitido extender la prueba a muestras que hasta ahora no podían ser objeto de la misma. Y, por otra parte, las intervenciones precisas para la obtención de muestras para la práctica de un análisis de ADN son cada vez menos invasivas, lo que desde el punto de vista jurídico facilita la práctica de la prueba (p. 3).

Por ello, consideramos importante que se desarrollen los aspectos más relevantes del procedimiento de la prueba de $\mathrm{ADN}$, para identificar sus peculiaridades que influir finalmente en su valoración probatoria por parte del juez de juicio, conforme a las reglas del CPP de 2004. 


\section{Procedimiento de la Prueba de ADN}

\section{a. El control de la toma de muestras biológicas}

En este punto se pueden apreciar tres momentos principales: el primero, referido al aseguramiento de las muestras, evitando su contaminación (cadena de custodia); el segundo referido al procedimiento de recojo propiamente; y el tercero, a la conservación del material biológico que será analizado.

En el primer momento, tenemos a la cadena de custodia, que puede entenderse como:

El conjunto de medidas que se deben adoptar a fin de preservar la identidad e integridad de las muestras, huellas o vestigios que pueden ser fuente de prueba en la comisión de un delito, como requisito esencial para su posterior validez probatoria (Del Olmo, 2011, p. 1550).

De igual manera, Romeo Casabona (2004) ha manifestado respecto de la exigencia de mantener un estricto cuidado de la muestra obtenida en la investigación, que la:

Incolumidad de la cadena de custodia de la muestra, se refiere al aseguramiento de la identidad y la adecuada conservación y custodia de la muestra biológica sobre lo que se realizan los análisis de $\mathrm{ADN}$ desde su obtención en el entorno del delito (la víctima, el lugar de los hechos) hasta que se incorpora definitivamente en el proceso como medio de prueba (p. 419).

Entonces, una adecuada cadena de custodia constituye el requisito esencial que debe estar presente durante todo el procedimiento, desde la obtención de la muestra hasta su análisis y posterior incorporación como medio de prueba, para acreditar su validez posterior durante su control de fiabilidad. Esto, con la finalidad de garantizar "sin ningún género de duda que las muestras o evidencias de la escena del crimen, sean las que efectivamente reciba el laboratorio" (Del Olmo, 2011, p. 1552).

En un segundo momento, es en el cual se realiza el procedimiento de recojo de muestra biológicas, la que debe seguir ciertas normas y requisitos que dependerán de donde y de quién se obtiene la muestra de ADN. En ese sentido, desde un sector de la doctrina española se pueden extraer valiosas consideraciones que deben ser tenidas en cuenta en esta fase del procedimiento pericial científica, que abarcan lo siguiente (Del Olmo):

De lugar o escenario del delito. La recogida de muestras biológicas del lugar o escenario del crimen es una diligencia de investigación criminal que suele realizar la policía en el marco de la diligencia de inspección ocular que suele tener lugar inmediatamente después de conocerse la comisión del delito. Si se realiza en un lugar público la policía puede, sin ningún requisito previo, proceder a la recogida de muestras genética o de cualquier otra clase o naturaleza que se hallaren en el lugar. También podrá la policía obtener muestras biológicas en lugares privados, que pueden ser almacenados en despachos o viviendas. (pp. 374375).

Del cuerpo del delito. Especial atención a la recogida de vestigios en el cuerpo de la víctima o de testigos. Las muestras biológicas pueden hallarse, en, o, sobre el cuerpo de la víctima, sus ropas u objetos personales, en su morada o bien en un lugar de su propiedad. 
Así suele suceder en los delitos de agresión sexual, de lesiones, homicidio o asesinato, supuestos en los que es probable que el agresor haya abandonado alguna muestra biológica que puede obtenerse del cuerpo o de los objetos de la víctima (...) Desde mi perspectiva la policía tiene la potestad de obtener las muestras de la víctima o testigo. Ahora bien ante la negativa lo más adecuado será que se solicite autorización judicial habilitante para la práctica de la diligencia (pp. 375-376).

Del sospechoso o imputado. La obtención de muestras biológicas del sospechoso o imputado sirve a la identificación material del presunto responsable del delito, que se producirá mediante su contraste con el perfil genético obtenido de las muestras recogidas en el lugar o en el cuerpo del delito. Se trata de una diligencia de investigación que está sometida al cumplimiento de las restricciones $y$ requisitos destinados a garantizar el estatus jurídico de la persona a la que se imputa un delito (p. 376).

En el tercer momento, se encuentra destinado a la conservación del material a analizar, es necesario contar con un ambiente adecuado para tal fin. En ese sentido, es indispensable que los laboratorios que se encargan de conservar y custodiar las muestras biológicas, "deben estar equipados de manera adecuada para garantizar una protección apta contra toda sustracción o la degradación, para garantizar la salvaguarda de las células, de las muestras y de los resultados de los análisis" (Vargas, 2010, p. 134).

\section{b. Posibles deficiencias del procedimiento.}

Entre los posibles riesgos para el procedimiento, de no llevarse a cabo con las medidas de precaución, están los siguientes:
- Contaminación. Entendida como la presencia de otros productos extraños de origen bioquímico o químico $\mathrm{o}$ de vestigios biológicos procedentes de otras personas que se encuentran junto con la muestra, existiendo un riesgo de que se contamine. También puede presentarse cuando existen indicios de diferentes personas que hayan intervenido de alguna manera en los hechos criminales, lo que llevaría a la confusión. Por último, la contaminación también puede presentarse cuando se confundan accidentalmente las muestras con otros restos biológicos producto de su exposición a fenómenos naturales, que puede darse por negligencia o por comportamiento doloso del personal técnico inclusive.

- Calidad y cantidad de la muestra. Puede ocurrir que las muestras recogidas sean minúsculas (pequeñas muestras de sangre, saliva) o que la cantidad de ADN no sea suficiente (el pelo posee $\mathrm{ADN}$ en su raíz y no en gran cantidad). También pueden degradarse las muestras como consecuencia del paso del tiempo (Vargas, 2010).

Para evitar tales riesgos, es indispensable que el personal científico técnico que pertenezca a estas instituciones, que en nuestro medio se encuentran adscritos al Instituto de Medicina Legal actúe con toda la diligencia posible para evitar que las pruebas sean declaradas inadmisibles por el juzgador o desacreditadas por las partes. Por ello, consideramos que estos requisitos deben ser cumplidos por la cadena de custodia conforme a las reglas del CPP de 
2004 y la normativa administrativa aplicable a tales efectos.

\section{La cadena de custodia}

En principio, conviene precisar que la importancia de la cadena de custodia ha sido propiciada por las críticas a los resultados de la prueba científica de $\mathrm{ADN}$, debido principalmente a los peligros de contaminación y manipulación indebida que siempre pueden ocurrir en este tipo de diligencias. Así pues, en la doctrina se ha precisado que la desconfianza hacia la prueba de ADN proviene precisamente desde el método o procedimiento de la recogida de los vestigios y más aún, si estos corresponden a elementos o materiales biológicos, por ello, es que como recomendación se opta por

Observar estrictos estándares de aseguramiento y preservación a través de la cadena de custodia. Conseguido este primer propósito, se puede afirmar que el resultado del análisis de ADN permitirá en gran porcentaje de probabilidad, establecer adecuadamente la persona vinculada con una investigación penal (Vargas, 2010, p. 130).

En nuestro ordenamiento procesal penal la definición de cadena de custodia no se encuentra descrita explícitamente, pero si su aplicación y finalidad como procedimiento anexo a medidas de búsqueda de pruebas y restricción de derechos, con la finalidad de resguardar los elementos o efectos del delito de diversa naturaleza. Por ello, para brindar una definición es necesario remitirse al Protocolo de Actuación Interinstitucional para la aplicación de la incautación, comiso, hallazgo y cadena de custodia, aprobado mediante Decreto Supremo N ${ }^{\circ} 010-2018$ JUS, de 25 de agosto de 2018, en el cual se la define como:

\begin{abstract}
El procedimiento destinado a garantizar la individualización, seguridad y preservación de los elementos materiales y evidencias, recolectados de acuerdo a su naturaleza o incorporados en toda investigación de un hecho punible, destinados a garantizar su autenticidad, para los efectos del proceso. Las actas, rótulos, formularios y embalajes forman parte de la cadena de custodia (punto 1.4).
\end{abstract}

De igual manera, San Martín (2015) refiere que la cadena de custodia "no es más que un mecanismo para demostrar la autenticidad del cuerpo del delito, como concepción amplia, incautado durante la etapa de investigación preparatoria" (p. 344). Asimismo, el citado autor, también lo encuadra como un conjunto de formalidades que asegura la integridad de los elementos o vestigios recogidos $y$, finalmente, también puede entenderse como un mecanismo que acredita la veracidad o autenticidad del cuerpo del delito (San Martín, 2015). Todos estos aspectos, actuados conjuntamente permiten que las muestras obtenidas y que serán materia de análisis en la prueba científica de $\mathrm{ADN}$, no puedan ser cuestionadas en estos aspectos.

El artículo 220 inciso 5 del CPP de 2004, en esa misma línea es muy claro al afirmar que: "la Fiscalía de la Nación, a fin de garantizar la autenticidad de lo incautado, dictará el Reglamento correspondiente a fin de tomar el diseño y control de la cadena de custodia"; por ello, el protocolo de actuación interinstitucional ha dispuesto la actividad que debe seguir la Policía Nacional en los casos que la incautación sea realizada en el marco de una intervención en flagrancia, así dispone que:

La cadena de custodia se inicia con el aseguramiento, inmovilización 
y/o recojo de los elementos materiales y evidencias, durante la intervención.

Los elementos materiales, evidencias y bienes incautados se registrarán en el formato de la cadena de custodia mediante una descripción minuciosa y detallada de las características, medidas, peso, tamaño, color, especie, estado entre otros datos del medio en el que se encontraron, de las técnicas utilizadas en el recojo de las pericias que se dispongan, en el cual no se admiten enmendaduras. En caso de que amerite una corrección, ésta se efectuará entre paréntesis en el mismo documento, explicando los motivos que la generaron.

Los bienes materiales y las evidencias recolectadas $\mathrm{o}$ incorporadas deberán ser debidamente rotulados y/o etiquetados para su correcta identificación, seguridad e inalterabilidad. (paso 2 y 3 )

Asimismo, en el marco de una incautación mediante disposición fiscal, se establece que el "personal dará cumplimiento a lo dispuesto por el/la Fiscal (...) iniciará el procedimiento de cadena de custodia de bienes incautados" (punto 6) y finalmente, en los casos de la incautación realizada en ejecución de una resolución judicial, se precisa que "El/la Fiscal, dispondrá, conforme a la naturaleza del caso, que se levante la cadena de custodia de los bienes incautados" (punto 10); estos pasos con comunes para los casos de la diligencia de comiso y en caso de hallazgos durante una intervención policial.

Por lo expuesto, cabe preguntarse si la ruptura de la cadena de custodia significa en todos los casos que las muestras obtenidas han sido alteradas o contaminadas. Al respecto, San Martín (2015) ha sostenido que no necesariamente debería declararse la ineficacia probatoria de la prueba científica de haberse verificado la ruptura de la cadena de custodia, por los siguientes argumentos:

Será necesario que la parte - no solo la parte acusadora, que por ley debe seguir el procedimiento en cuestión para garantizar la mismidad de la prueba - que incorpore esos elementos materiales pueda acreditar la autenticidad del cuerpo del delito en sus ámbitos esenciales por otros medios de prueba, más allá de la prueba documentada que dimana del acta de incautación y de los formatos respectivos de cadena de custodia (...) la alegación de la simple posibilidad de su rompimiento, manipulación o contaminación, no es aceptable. Debe acreditarse tal alegación (pp. 347-349)

\section{El informe pericial científico.}

El informe pericial científico que contenga los resultados del procedimiento científico de ADN, debe contener todos los requisitos establecidos para el artículo $178^{\circ}$ del CPP de 2004, dentro de los cuales, conviene resaltar los siguientes:

c) La exposición detallada de lo que se ha comprobada en relación al encargo.

d) La motivación o fundamentación del examen técnico.

e) La indicación de los criterios científicos o técnicos, médicos $\mathrm{y}$ reglas de los que se sirvieron para hacer el examen.

f) Las conclusiones.

Estos requisitos que deben constar en el informe pericial científico se han establecido con la finalidad de que puedan ser sometidos a un examen probatorio en el juicio oral, con la exposición del informe 
por parte del perito científico y puedan ser valorados por el Juez y motivados en la sentencia penal.

\section{EL VALOR PROBATORIO DE LA PRUEBA DE ADN EN EL PROCESO PENAL PERUANO.}

La doctrina ha precisado que la valoración de la prueba es "la operación mental que tiene por fin conocer el mérito o valor de convicción que puede deducirse de su contenido" (Devis, 2002, p. 273). Esta operación mental es exclusiva del juez y por tanto las partes son quienes aportan los medios probatorios dirigidos a generar una certeza en el juzgador. El objetivo de la valoración es determinar el grado de corroboración que el material probatorio aporta a cada una de las posibles hipótesis fácticas en conflicto (Ferrer, 2007); es decir, la valoración de la prueba requiere de un trabajo de comparación entre hechos postulados y los elementos requeridos para probarlos a fin de determinar cuáles son verdaderas o que efectivamente se condicen con la realidad (Climent, 2005).

Ahora bien, dentro de los sistemas de valoración probatoria (legal o tasada, íntima convicción y libre convicción o sana crítica), es el sistema de sana crítica que ofrece mayor margen para la libre valoración de las pruebas, debido a que:

Este sistema se caracteriza por la posibilidad de que el magistrado obtenga conclusiones sobre los hechos de la causa, valorando la prueba con total libertad, pero respetando al hacerlo los principios de la recta razón, es decir las normas de la lógica, la ciencia y la experiencia común (Talavera, 2009, p. 108).

Por ello, en las siguientes líneas desarrollaremos el tratamiento normativo de la prueba pericial en nuestro sistema procesal penal, desde el Código de Procedimientos Penales de 1940 hacia el tránsito al CPP de 2004, que acoge un desarrollo íntegro de la prueba pericial.

\section{En el Código de Procedimientos Penales de 1940}

En el Código de Procedimientos Penales de 1940 (en adelante C. de PP) la valoración de la prueba se regía bajo el sistema de libre convicción, no adscribiéndose con ello al sistema de prueba legal o tasada que regía para el Código de Enjuiciamiento en Materia Penal de 1863. Sin embargo, si bien dicho Código de Procedimientos Penales se adscribía al sistema de íntima convicción, bajo el llamado criterio de conciencia previsto artículo $283^{\circ}$, en modo alguno constituía un criterio positivo, pues no se establecía ningún deber de motivación del razonamiento probatorio que realizó el juez en la valoración de la prueba penal.

En cuanto a la valoración de la prueba pericial, encontramos que, en el C. de PP, en los art. $160^{\circ}$ al $169^{\circ}$ se establecen los requisitos y formalidades que debe seguir una pericia para ser incorporada válidamente al proceso penal. Sin embargo, no se establece normativamente un criterio especial de valoración de la prueba pericial, de ahí que la misma doctrina haya señalado que

Al igual que los demás medios probatorios, el dictamen pericial tiene el valor que el juzgador conceda por sí solo y con relación a los otros elementos probatorios (...) Habrá de tener en cuenta la competencia y conocimiento de los peritos, los principios científicos en que apoyan su informe, su concordancia con los principios lógicos y demás pruebas. El dictamen pericial no determina la sentencia judicial, aunque puede ser importante para ella. Es el juez que 
resuelve y no el perito (Sánchez, 2004, p. 502).

\section{En el Código Procesal Penal de 2004}

El Código Procesal Penal de 2004 se acoge íntegramente al sistema de la sana crítica o de libre convicción. En este sistema se observan tres reglas principales en las cuales debe basarse el juzgador para valorar las pruebas, que se encuentran referidas a la aplicación de los principios o reglas de la lógica, las reglas o máximas de la experiencias y las reglas de la ciencia o los conocimientos científicos para valorar la prueba penal, tal y como se recoge en el art. $158^{\circ}$ inciso 1 , es decir, a diferencia del Código de Procedimientos Penales de 2004, se establece un criterio racional de valoración donde el juez al momento de valorar la prueba deba seguir estas reglas que orientan su criterio jurídico.

Asimismo, en lo que se refiere a la pericia, nuestro código establece previamente en el art. $170^{\circ}$ al $181^{\circ}$ los requisitos, formalidades y contenido de la prueba pericial, a fin de que sea ingresada debidamente al proceso penal. Si bien, no se establece un criterio de valoración propio para la prueba pericial, el juzgador según el criterio de valoración general del art. $158^{\circ}$ inc. 14 del CPP, deberá valorarla de acuerdo a las reglas de la lógica, la ciencia y las máximas de la experiencia. El legislador siguiendo el sistema de valoración de la sana crítica ha dejado la valoración de la prueba pericial al juzgador quien tiene la labor de valorar la prueba conforme a estas reglas.

\section{La importancia de la prueba científica de ADN en los delitos sexuales.}

La evolución tecnológica científica, así como su veloz crecimiento han introducido en los procedimientos de aportación de prueba, dentro de los procesos de reforma de justicia, fórmulas novedosas $y$ sofisticados y con altos grados de fiabilidad que ha en crecimiento como contribución en la administración de justicia en general. Esto es debido a que las pruebas científicas no solo se han limitado al reconocimiento e identificación de personas sino también han introducido métodos que permiten el descubrimiento de evidencias sumamente imperceptibles y que en muchas ocasiones terminan siendo fundamentales para el descubriendo de la verdad material dentro del proceso.

Ello ha sido posible debido al avance de la ciencia en el mundo moderno, ello produce una significativa ampliación y consecuente especialización en conocimientos científicos y técnicos. Las pruebas biológicas, por su idoneidad han adquirido a lo largo de los años, conforme a su evolución científica mayor relevancia para dilucidar una amplia gama de cuestiones, que permiten más allá de lo tradicional en $\mathrm{su}$ incidencia en el reconocimiento de personas en lograr también el esclarecimiento de delitos.

En la actualidad, la prueba científica se ha posicionado como una técnica de alta concurrencia y utilidad para el esclarecimiento de investigaciones criminales, sobre todo su incidencia se da en delitos de violación sexual (Hernández, 2001). El estudio de este tipo de pruebas científicas, en la actualidad, arrojan resultados sumamente exactos, ya sean tomadas las muestras de sangre, semen, saliva o de algún tejido biológico, casi ningún juez puede rechazarla, ello debido a su alto grado de fiabilidad conforme al avance de la ciencia y el escaso cuestionamiento que merecen dichos tipos de prueba.

Finalmente, el uso de las pruebas biológicas, pruebas científicas o pruebas de $\mathrm{ADN}$, en la actualidad tienen mayor incidencia en su utilización $\mathrm{y}$ un crecimiento sobresaliente dentro del 
proceso penal, ya que no solo se limitan al reconocimiento de identidad de personas, sino también con gran éxito permiten el esclarecimiento de los hechos materia de investigación. Ello se desarrolla con mayor impulso en delitos relacionados a violación sexual debido al alto requerimiento según las circunstancias del hecho y con menor incidencia en otros delitos pero que no por ello pierde su relevante importancia.

Las pruebas de $\mathrm{ADN}$, como todo tipo de prueba, también contiene un margen de error que debe ser considerado para su estudio como medio de prueba, así como debe pasar por filtros de admisión para adherirse al proceso y durante su valoración se debe efectuar una adecuado control de este; debe respetar requisitos tradicionales como lo son los de pertinencia, necesidad y legalidad, así como cruzar la barrera del control probatorio y respetar el estándar de fiabilidad probatoria, todo esto lo desarrollaremos con mayor amplitud en los siguientes apartados.

\section{Los laboratorios y técnicas en el procedimiento de ADN utilizadas en la práctica forense peruana}

En el ámbito penal peruano, el laboratorio autorizado para realizar los procedimientos de ADN, es el Laboratorio de Biología Molecular y de Genética (LABIMOG) que forma parte de la Unidad que lleva el mismo nombre del Instituto de Medicina Legal del Ministerio Público. Este laboratorio "se creó después del luctuoso incendio ocurrido en el cercado de Lima "Mesa Redonda" de 29 de diciembre de 2001 (...) para ayudar en la identificación de los desaparecidos" (Ministerio Público, 2020) y, es el encargado de realizar "la aplicación de metodologías científicas y el desarrollo de técnicas moleculares y genéticas en la resolución de procesos de filiación e identificación forense" (Ministerio Público, 2020).
La página web de la Unidad de Biología Molecular y de Genética, es muy precisa cuando describe las áreas específicas que desarrollan cada uno de los aspectos del procedimiento de $\mathrm{ADN}$, las que son:

Áreas específicas para cada proceso: Evaluación y Tratamiento de muestras de Criminalísticas, procesamiento de Restos Óseos, Extracción del ADN, Cuantificación de ADN, Amplificación de ADN y el Análisis de Perfiles Genéticos, dentro de las cuales se cuenta con equipos automatizados de alta tecnología, soporte informático y Software adecuados para cada proceso.Los Sistemas Genéticos con los que trabajamos comprende, Marcadores STR autosómicos del CODIS (norteamericanos), Marcadores STR autosómicos los del ENFSI (Europeos), Marcadores MiniSTR, Marcadores STR del Cromosoma Y, Marcadores STR del Cromosoma X y Marcadores de inserción $\mathrm{y}$ delecciones $\mathrm{y}$ Secuenciación de ADN Mitocondrial (Ministerio Público, 2020, p. 1).

Asimismo, entre los principales equipos que se utilizan son los siguientes: "BSD Punching Automatizado para tarjetas FTA; FreezerMill para el tratamiento de Restos Óseos; Real Time PCR 7500 para cuantificación de ADN; QAgility automatizado para preparación PCR; Termocicladores para PCR; Analizador Genético Automátizado ABI 3500" (Ministerio Público, 2020).

Como se puede apreciar, los laboratorios que integran el Instituto de Medicina Legal adscrito al Ministerio Público, se encuentran equipados con los implementos necesarios para realizar los procedimientos de ADN acordes con las recomendaciones de la doctrina y práctica científica, tal es así 
que a partir del año 2019 se vienen realizando no solo los análisis de ADN para casos penales (delitos sexuales, homicidios, entre otros), sino también, para casos de filiación. Al respecto cabe señalar, que esta labor científica de análisis de ADN es una facultad y atribución propia del Estado, solo en determinadas circunstancias se le pueden encomendar esta labor a las Universidades, Institutos $u$ Organizaciones que se encuentren debidamente calificadas e inscritas para esta labor.

Para finalizar este apartado, hay que dejar establecido que la finalidad de este artículo es desarrollar los criterios judiciales, más no científicos, para valorar y motivar el razonamiento sobre la fiabilidad y eficacia de la prueba de ADN en el proceso penal; en tal sentido, los procedimientos científicos son universales y han sido desarrollados en el apartado correspondiente, no obstante, es una tarea pendiente realizar un análisis de campo para identificar si los laboratorios dedicados a realizar estos procedimientos cumplen con las exigencias científicas requeridas en nuestro ambiente judicial penal.

\section{Criterios establecidos por el Acuerdo Plenario $N^{\circ}$ 4-2015/CIJ-116.}

El Acuerdo Plenario $\mathrm{N}^{\circ}$ 4-2015/CIJ-116 emitido por la Salas Penales Permanente y Transitorias de la Corte Suprema de Justicia, de 2 de octubre de 2015, es relevante porque fija criterios generales para la valoración de la prueba pericial aplicable a toda clase de pericias y en específico, para la pericia científica en casos de delitos sexuales. Acoge los criterios establecidos previamente desde el derecho comparado, en concreto los establecidos en el caso Daubert del Derecho norteamericano, adaptándolos a nuestro medio procesal penal. Antes de desarrollar estos criterios, conviene precisar previamente los controles que han sido establecidos en la doctrina a partir del caso Daubert.

\section{a) El control de Fiabilidad y Validez (Estándar Daubert)}

Los estándares de fiabilidad y el control de validez científica surgen a raíz de la desconfianza que suscitó las serias deficiencias que se encontraron en el método de realización de las pruebas científicas, en especial las pruebas de ADN en los países anglosajones (Taruffo, 2008). Así, se advirtió la carencia de criterios que permitan valorar la fiabilidad del método científico realizado en las pericias. En ese sentido, la jurisprudencia estadounidense buscó realizar un Juicio de Fiabilidad o de confianza en las pruebas científicas, consistentes en

La verificación de la concurrencia de ciertos requisitos y de las características que debe cumplir el concreto medio de prueba para ser valorado por el juez a fin de que en condiciones de idoneidad tanto formal como material pueda servir para acreditar un enunciado fáctico (Castillo, 2013, p. 309).

Al respecto, la jurisprudencia estadounidense se ha pronunciado en diversas oportunidades respecto a la valoración de los dictámenes periciales, siendo el caso Daubert el más resaltante, al establecer criterios para la determinación de su fiabilidad. En ese caso se advierte que "Daubert fue una serie de casos relacionados con la droga Bendectin, ampliamente prescrita para aliviar las naúseas matutinas. Los denunciantes alegaron que la droga causó defectos de nacimiento" (Sanders, 2012, p. 100).

En ese sentido, Haack (2012) refiere que:

La Corte Suprema de Justicia (del estándar) Daubert sostuvo que la regla Frye había sido reemplazada, por el gobierno nacional, mediante 
la FRE 702 (1975) (Regla Federal de Evidencia 702), la cual estipuló que el dictamen pericial es admisible si es relevante y de ninguna manera está excluido por la ley ( $\sin$ mencionar la aceptación general); pero que las Cortes Nacionales todavía tuvieran la responsabilidad del control del dictamen pericial, incluido el testimonio científico, tanto para la pertinencia como para la fiabilidad (pp. 335-336).

En la determinación de la fiabilidad, el Juez Blackmun sugirió que las Cortes podrían mirar hacia los siguientes indicios, ahora conocidos como los factores Daubert, los cuales pueden ser (Haack, 2012, p 336):

i)Si la teoría o la técnica utilizada puede ser (y ha sido) corroborada;

ii) Si esta ha estado sujeta a revisión por pares y a publicación;

iii) El conocimiento del margen potencial del error; $y$

iv) Si el trabajo en que se basa el testimonio ha ganado amplia aceptación en el campo relevante.

En base a esta jurisprudencia, se observan criterios que nos permitan determinar la fiabilidad de la pericia o prueba científica, analizando con objetividad su método y procedimiento aplicado a cada caso concreto. Se tiende a pensar que, debido a la alta fiabilidad del método $y$ procedimientos de la prueba de ADN, los resultados no pueden ser objetados o sometidos a un examen de falibilidad. Sin embargo, como se ha precisado anteriormente los controles que deben realizarse van en dos sentidos: el primero es la fiabilidad de la prueba y el segundo, respecto de su valoración y peso para determinar los hechos relevantes para el caso penal.

\section{b) Los criterios establecidos por la Corte Suprema para la valoración de la prueba científica de ADN}

Al respecto, las Salas Permanente y Transitorias de la Corte Suprema en el Acuerdo Plenario No 4-2015/CIJ-116, han establecido criterios de análisis y valoración para la prueba pericial científica, partiendo por señalar que estos se inspiran en la experiencia judicial norteamericana, que adaptados a nuestro modelo procesal penal tiene como resultado los siguientes criterios:

D) Si la prueba es científica desde un primer nivel de análisis, debe evaluarse si esta prueba pericial se hizo de conformidad con los estándares fijados por la comunidad científica. El juez al momento de evaluar al perito debe examinar sobre la relevancia y aceptación de la comunidad científica de la teoría utilizada, y cómo es que su uso apoya la conclusión a la que arribó. De ser notoria la relevancia y aceptación de la teoría, esto no será necesario. Asimismo, el juez debe apreciar el posible grado de error de las conclusiones a las que ha llegado el perito (Corte Suprema, Acuerdo Plenario $\quad \mathrm{N}^{\circ} \quad 4-2015 / \mathrm{CIJ}-116$, fundamento 22).

Así pues, asumiendo el estándar Daubert, el juez deberá valorar: 1 . Si la prueba pericial científica cumple con los estándares fijados por la comunidad científica, para lo cual, deberá conocer cuáles son las reglas que ha utilizado para su labor pericial; y 2. El grado de error que puede evidenciarse del procedimiento pericial. Cabe señalar que estos criterios deben ser valorados conjuntamente con los otros que también establece el citado acuerdo plenario; así, solo tendría eficacia el informe pericial científico de $\mathrm{ADN}$ que, además 
Haberse elaborado de acuerdo con las reglas de la lógica $\mathrm{y}$ conocimientos científicos o técnicos. Especialmente, si se analiza el objeto del dictamen, la correlación entre los extremos propuestos por las partes y los expuestos del dictamen pericial, y la correspondencia entre los hechos probados y los extremos del dictamen, la existencia de contradicciones entre el informe y lo vertido por el perito en el acto oral (Corte Suprema, Acuerdo Plenario $\mathrm{N}^{\circ}$ 4-2015/CIJ-116, fundamento 22).

Esta postura ha sido confirmada en la Casación $\mathrm{N}^{\circ}$ 292-2014-Ancash, de fecha 17 de febrero de 2016, emitido por las Salas Penales Permanentes y Transitorias de la Corte Suprema, que al analizar la eficacia de la prueba científica de ADN ha señalado que

Al haberse ofrecido la prueba de ADN tomándose las muestras pertinentes, dentro del plazo y con las formalidades que exige la ley, resulta insostenible soslayar la compulsa y su valoración de dicha prueba, para llegar a la certeza del tema probandum y la responsabilidad del recurrente (Corte Suprema, Casación No 2922014-Ancash, fundamento jurídico 3.3.3).

\section{El juez como epistemólogo}

Quizás uno de los criterios más importantes que ha precisado la Corte Suprema ha sido el resaltar la valoración de la prueba científica por parte del Juez, lo que nos lleva a desterrar el mito de la infalibilidad de la ciencia. No se trata solo de hacer referencia a la vieja definición del juez como peritus peritorum, sino que debe ser responsable de la valoración de la prueba científica en lo respecta a la metodología que utilizó el experto, lo que no debe ser interpretado como una sustitución del juez por el experto. Así es que el juez debe realizar una valoración crítica en cuanto a la metodología empleada en el procedimiento para realizar la prueba científica de $\mathrm{ADN}$, lo que incidirá necesariamente en el valor probatorio que se le brinde en la sentencia penal (Taruffo, 2012).

En ese sentido, suscribimos las palabras de Taruffo (2012), que señala:

Que el juez deba operar como un peritur peritorum - por usar una fórmula tradicional- significa que el juez debe controlar esto que el experto ha hecho, con la finalidad de verificar la validez y la credibilidad del resultado que deriva de la prueba científica. Como quiera el juez debe valorar la correcta realización del procedimiento y la validez del método que ha sido seguido en la realización de la prueba científica. Por decirlo con una fórmula sintética, el juez no debe transformarse en un científico (cosa que lo transformaría en un apprenti sorcier, de lo cual no se siente verdaderamente necesidad), pero debe operar como un epistemólogo, es decir, como un sujeto que verifica la validez del método con el cual han estado uniendo determinados resultados probatorios (p. 40).

Lo expuesto encuentra respaldo jurisprudencial por parte de la Corte Suprema, cuando respecto a la participación del juez en la valoración de la prueba científica, señala:

El juez frente a la prueba científica de ADN no debe eximirse de realizar el trabajo de valoración. Es responsabilidad del juez interpretar esos resultados correctamente $\mathrm{y}$ 
atribuirles un determinado peso en la formación de su convicción sobre el hecho principal. Ello es importante, pues no es lo mismo que la prueba guarde una relación directa con el hecho principal que se pretende probar o que la prueba proporcione tan solo un indicio más para probar ese hecho principal (Corte Suprema de Justicia, Casación $\quad \mathrm{N}^{\circ}$ 292-2014-Ancash, fundamento jurídico 3.2.14).

\section{CONCLUSIONES}

La prueba pericial constituye un medio de prueba que tiene por finalidad brindar conocimientos especializados al juez penal, a fin de que pueda valorar dicho conocimiento en la apreciación de los hechos del caso.

La importancia de la prueba pericial radica en la complejidad de muchos de los asuntos que se deben dilucidar en el proceso penal, la cual queda descubierta en la posición funcional del juez, que puede revelar sus carencias y limitaciones respecto de los mismos, ello precisamente es lo que ha hecho cobrar al perito un inusitado protagonismo probatorio.

En el Código de Procedimientos Penales de 1940, en lo referente a la valoración de la pericia, se establecían solamente los requisitos formales para su admisión. No existía propiamente un criterio para valorar la prueba pericial.

En el Código Procesal Penal del 2004, la valoración de la prueba sigue el sistema de libre valoración de la prueba o sana crítica, que impone la apreciación de la prueba conforme a las reglas de la lógica, la ciencia y las máximas de la experiencia. En lo que se refiere a la prueba pericial existe un mayor desarrollo en cuanto a los requisitos para su admisibilidad en el proceso penal, siendo sometida su valoración por el Juez a las tres reglas del sistema de la sana crítica.

En el sistema de la sana crítica si bien existen reglas para la valoración probatoria, para la valoración de la pericia, se deben tener criterios de control no solo para su admisibilidad como se encuentra actualmente regulado sino también, debe existir un control de fiabilidad de la pericia con la finalidad de que si se actuará en el proceso penal genere mayor certeza en el Juez de la veracidad de sus resultados.

La jurisprudencia norteamericana en el Caso Daubert ha establecido un estándar de valoración de la pericia, estableciendo con ello criterios para determinar su fiabilidad en el proceso penal. Estos pueden ser aplicados conjunta o separadamente por el Juez al momento de valorar la pericia.

El estándar Daubert tiene entre sus principales criterios que debe cumplir toda pericia los siguientes: a) Que la teoría o técnica haya sido corroborada previamente; b) Que haya sido sujeta a publicación y revisión por la comunidad científica; c) Que se establezca el potencial margen de error; d) si el trabajo en que se basa el testimonio ha ganado amplia aceptación en el campo relevante.

La importancia del Juez en la aplicación de un estándar de valoración de la pericia radica en su actuación como "peritur peritorum" (perito de peritos) o epistemólogo, es decir, que al momento de valorar la pericia no debe eximirse de hacer un control de su validez probatoria y con ello validar el procedimiento metodológico por el cual se llegó a dichos resultados.

Dentro de las pruebas periciales se encuentra la prueba de $\mathrm{ADN}$ que es frecuentemente utilizada en las investigaciones criminales sobre todo en los delitos contra la libertad sexual, debido a la exactitud de sus resultados. Sin embargo, la 
prueba de ADN como toda prueba pericial tiene un procedimiento o metodología a seguir, por tanto, también posee un margen de error en cuanto a la fiabilidad de sus resultados debido al peligro que existe de que se contamine o adultere las muestras que son objeto de análisis.

Es indispensable que exista un control de fiabilidad probatoria de la prueba de ADN, con la finalidad de que exista una mayor certeza de que los resultados obtenidos han sido producto de un debido procedimiento.

\section{FUENTTES DE INFORMACIÓN}

\section{Fuentes bibliográficas}

Abel Lluch, X. (2012). La valoración de la prueba cientifica. En M. Bustamante (Coord.). Derecho probatorio contemporáneo, prueba científicas y técnicas forenses. Medellín, Colombia: Universidad de Medellín.

Caferatta Nores, J. y I. Hairabedian, M. (2008). La Prueba en el Proceso Penal. Con especial referencia a los códigos procesales penales de la Nación y de la Provincia de Córdova. 6ta edición. Buenos Aires, Argentina: Editorial Lexis Nexis.

Castillo Alva, J. (2013). La motivación de la valoración de la prueba penal. Lima, Perú: Editorial Jurídica Grijley.

Climent Durán, C. (2005). La prueba penal. Tomo I. 2da. Edición. Valencia, España: Editorial Tirant lo Blanch.

Del Olmo, J. (2011). Las Garantías Jurídicas de la Toma de Muestras Biológica para la identificación de la persona imputada mediante el ADN. En: Joan Pico i Junoy, Xavier Abel Lluch y Manuel Gonzales. La Prueba Judicial. Desafíos en las jurisdicciones civil, penal, laboral y contencioso - administrativo. Tomo II. Madrid, España: Editorial La Ley.
Denti, V. (1974). Estudios de derecho probatorio (Traducción de Santiago Sentís Melendo y Tomás A. Banzhaf). Buenos Aires, Argentina: Ediciones Jurídicas Europa-América.

Devis Echandía, H. (2002). Teoría General de la Prueba Judicial. Bogotá, Colombia: Editorial Temis.

Ferrajoli, L. (1995). Derecho y razón. Teoría del garantismo penal (Traducción de Perfecto Andrés Ibañez y otros). Madrid, España: Editorial Trotta.

Ferrer Beltrán, J. (2007). La valoración racional de la prueba. Madrid, España: Marcial Pons.

González, M. (2012). La obtención, análisis y prueba de muestras biológicas obtenidas del lugar, del cuerpo del delito o mediante la intervención sobre el sospechoso o imputado. En Mónica Bustamante Rúa (Coord.). Derecho probatorio contemporáneo. Prueba científica y técnicas forenses. Medellín, Colombia: Universidad de Medellín.

Guzmán, N. (2011). La verdad en el proceso penal. Una contribución a la epistemología jurídica. 2da. Edición. Buenos Aires, Argentina: Editores del Puerto S.R.L.

Haack, S. (2012). Técnicas forenses, litigios impulsados por la ciencia, y el problema de los incentivos perversos: lecciones a partir de la saga Ramírez. En Mónica Bustamante Rúa (Coord.). Derecho probatorio contemporáneo. Prueba científica y técnicas forenses .Medellín, Colombia: Universidad de Medellín.

Neyra Flores, J.A. (2010). Manual del nuevo proceso penal \& de litigación oral. Lima, Perú: Idemsa. 
Nieva Fenoll, J. (2012). Fundamentos de Derecho procesal penal. Buenos Aires, Argentina: Euros Editores S.R.L.

Pabón Parra, P. (2015). La prueba pericial. Sistema acusatorio. Partes general y especial. 2da. Edición. Bogotá, Colombia: Ediciones Doctrina y Ley LTDA.

Sánchez Velarde, P. (2004). Manual de Derecho procesal penal. Lima, Perú: Editorial IDEMSA.

Sanders, J. (2012). La paradoja de la relación metodología y conclusión y la estructura de la decisión judicial en los Estados Unidos. (Traducido por Dimaro Agudelo Mejía). En: Mónica Bustamante Rúa (Coord.). Derecho probatorio contemporáneo. Prueba científica y técnicas forenses. Medellín, Colombia: Universidad de Medellín.

San Martín Castro, C. (2015). Derecho procesal penal. Lecciones. Conforme al código procesal penal de 2004. Lima, Perú: Instituto Peruano de Criminología y Ciencias Penales.

Talavera Elguera, P. (2009). La prueba en el nuevo proceso penal. Manual del Derecho probatorio y de la valorización de las pruebas en el proceso penal común. Lima, Perú: Academia de la Magistratura AMAG.

Taruffo, M. (2010). Simplemente la verdad: El juez y la reconstrucción de los hechos. (Traducción de Daniela Accatino Scaglioti). Madrid, España: Marcial Pons.

Taruffo, M. (2008). La prueba (Traducción de Laura Manríquez y Jordi Ferrer Beltrán). Madrid, España: Marcial Pons Ediciones Jurídicas y Sociales S.A.

Witthaus, R. E. (1991). Prueba Pericial. Buenos Aires, Argentina: Editorial Universidad.
Yábar Varas, C. (2003). Manual de procedimientos de electroforesis para proteínas y ADN. Lima, Perú: Ministerio de Salud, Instituto Nacional de Salud.

\section{Fuentes hemerográficas:}

Romeo, J. (2004). Los perfiles de ADN en el proceso penal: novedades y carencias del Derecho Español. Estudios de Derecho Judicial, 58 (1). pp. 411-476.

\section{Fuentes electrónicas}

Gascón Abellán, M. (2010). Prueba científica: Mitos y paradigmas. Anales de la Cátedra Recuperado de https://revistaseug.ugr.es/index.php/acfs/art icle/view/500/590.

Gascón Abellán, M (2007). Validez y valor de las pruebas científicas: La prueba del ADN. Recuperado de https://www.uv.es/cefd/15/gascon.pdf.

Gozaíni, O. (2012). La prueba científica no es prueba pericial. Revista Derecho \& Sociedad. Recuperado de http://revistas.pucp.edu.pe/index.php/derec hoysociedad/article/view/13116

Hernández Gómez, L (2001). La prueba de ADN, una Herramienta contundente en el esclarecimiento de los delitos de violación. Revista Latinoamericana de Derecho Médico Legal. Recuperado de https://es.scribd.com/document/381759862 /LA-PRUEBA-de-ADN-Una-HerramientaContundente-en-El-Esclarec-de-Delitosde-Violacion.

Ministerio Público (2020). Unidad de Biología Molecular y de Genética (UNBIOMOG). En página web: https://www.mpfn.gob.pe/iml/UNBIOMO $\mathrm{G} /$ 
Vargas Ávila, R. (2010). La Valoración de la Prueba Cientifica de ADN en el Proceso Penal. Prolegómenos. Derechos y Valores. Recuperado de https://www.redalyc.org/pdf/876/87617271 008.pdf.

Sistema Peruano de Información Jurídica (2018). Código Procesal Penal del año 2004. Actualizado al 18 de octubre de 2018. Recuperado de: http://spijlibre.minjus.gob.pe/normativa_li bre/main.asp.

Ministerio de Justicia (2018). Protocolo de actuación interinstitucional específico para la aplicación de la incautación, comiso hallazgo y cadena de custodia. Recuperado de https://legis.pe/2018-protocoloincautacion-comiso-hallazgo-cadenacustodia/.

\section{Jurisprudencia}

Salas Penales Permanente y Transitorias de la Corte Suprema de Justicia (2015). Acuerdo Plenario N 4-2015/CIJ-116.

Sala Penal Permanente de la Corte Suprema de Justicia (2016).Casación N²92-2014Ancash. 